\title{
Protective role of PI3-kinase/Akt/eNOS signaling in mechanical stress through inhibition of p38 mitogen- activated protein kinase in mouse lung
}

Xin-qi PENG ${ }^{1, \#, *}$, Mahendra DAMARLA ${ }^{2, \#}$, Jarrett SKIRBALL ${ }^{2}$, Stephanie NONAS ${ }^{5}$, Xiao-ying WANG ${ }^{7}$, Eugenia J HAN ${ }^{2}$, Emile $\mathrm{J} \mathrm{HASAN}^{2}$, Xuan $\mathrm{CAO}^{2}$, Adel BOUEIZ ${ }^{2}$, Rachel DAMICO ${ }^{2}$, Rubin M TUDER ${ }^{4}$, Alfred M SCIUTO ${ }^{1}$, Dana R ANDERSON ${ }^{1}$, Joe GN GARCIA $^{6}$, David A KASS ${ }^{3}$, Paul M HASSOUN ${ }^{2}$, Jun-tian ZHANG $^{7, *}$

${ }^{1}$ Division of Analytical Toxicology, US Army Medical Research Institute of Chemical Defense, Aberdeen Proving Ground, MD, USA; ${ }^{2}$ Division of Pulmonary \& Critical Care Medicine, ${ }^{3}$ Division of Cardiology, Department of Medicine, Johns Hopkins University School of Medicine, Baltimore, MD, USA; ${ }^{4}$ Division of Pulmonary Sciences and Critical Care Medicine, Department of Medicine, University of Colorado Denver School of Medicine, Denver, CO, USA; ${ }^{5}$ Oregon Health \& Science University, Division of Pulmonary and Critical Care Medicine, Portland, OR, USA; ${ }^{6}$ Department of Medicine, University of Chicago Pritzker School of Medicine, Chicago, IL, USA; ${ }^{7}$ Department of Pharmacology, Institute of Materia Medica, Chinese Academy of Medical Sciences, Beijing 100050, China

Aim: To test the hypothesis that PI3K/Akt/eNOS signaling has a protective role in a murine model of ventilation associated lung injury (VALI) through down-regulation of p38 MAPK signaling.

Methods: Male C57BL/J6 (wild-type, WT) or eNOS knockout mice $\left(\mathrm{eNOS}^{-1}\right.$ ) were exposed to mechanical ventilation (MV) with low (LV $\mathrm{T}_{\mathrm{T}}$, $7 \mathrm{~mL} / \mathrm{kg}$ ) and high tidal volume $\left(\mathrm{HV}_{\mathrm{T}}, 20 \mathrm{~mL} / \mathrm{kg}\right.$ ) for $0-4 \mathrm{~h}$. A subset of WT mice was administered the specific inhibitors of PI3K (100 $\mathrm{nmol} / \mathrm{L}$ Wortmannin [Wort], ip) or of p38 MAPK (SB203580, $2 \mathrm{mg} / \mathrm{kg}$, ip) $1 \mathrm{~h}$ before MV. Cultured type II alveolar epithelial cells C10 were exposed to $18 \%$ cyclic stretch for $2 \mathrm{~h}$ with or without $20 \mathrm{nmol} / \mathrm{L}$ Wort pretreatment. At the end of the experiment, the capillary leakage in vivo was assessed by extravasation of Evans blue dye (EBD), wet/dry weight ratio and lung lavage protein concentration. The lung tissue and cell lysate were also collected for protein and histological review.

Results: MV decreased PI3K/Akt phosphorylation and eNOS expression but increased phospho-p38 MAPK expression along with a lung leakage of EBD. Inhibitions of phospho-Akt by Wort worsen the lung edema, whereas inhibition of p38 MAPK kinase restored activation of Akt together with alleviated capillary leakage. $\mathrm{eNOS}^{-/}$mice showed an exacerbated lung edema and injury. The stretched C10 cells demonstrated that Wort diminished the activation of Akt, but potentiated phosphorylation of MAPK p38.

Conclusion: Our results indicate that PI-3K/Akt/eNOS pathway has significant protective effects in VALI by preventing capillary leakage, and that there is a cross-talk between PI3K/Akt and p38 MAPK pathways in vascular barrier dysfunction resulting from VALI.

Keywords: mechanical stress; ventilator-associated lung injury; pulmonary capillary leakage; PI3K/Akt/eNOS; p38 MAPK signalings; signals cross-talk; pulmonary edema; wortmannin

Acta Pharmacologica Sinica (2010) 31: 175-183; doi: 10.1038/aps.2009.190

\section{Introduction}

Acute lung injury (ALI) is a complex syndrome marked by increased vascular permeability resulting in tissue edema and profound hypoxia ${ }^{[1,2]}$. Mechanical ventilation (MV) is often a necessary treatment for respiratory failure and a supportive measure in critically ill patients. However, it is well known

\footnotetext{
\# These authors contributed equally to this work.

* To whom correspondence should be addressed.

E-mail xinqipeng@gmail.com (Xin-qi PENG) zhangjt@imm.ac.cn (Jun-tian ZHANG)

Received 2009-09-25 Accepted 2009-12-03
}

that ventilation with high tidal volume $\left(\mathrm{HV}_{\mathrm{T}} \mathrm{MV}\right)$ or pressure may be harmful, causing damage to previously healthy lungs or worsening already injured ones. This is especially the case for permeability whereby exacting mechanical stress on various components of the respiratory system can lead to ventilation associated lung injury (VALI). We performed the study described herein in an effort to elucidate the underlying mechanisms of VALI and investigate potential therapies against VALI.

Akt (protein kinase B), a multifunctional serine-threonine protein kinase, is a major downstream signaling molecule of phosphoinositide 3-kinase (PI3K). It is also an upstream 
enzyme of eNOS. Its activation has been implicated in various endothelial functions, including cell survival, migration, and activation of nitric oxide synthase ${ }^{[3-5]}$. Studies in vitro have shown that Akt can directly phosphorylate endothelial nitric oxide (NO) synthase (eNOS) and activate the enzyme, leading to NO production ${ }^{[6]}$. Thus the PI3K/Akt/eNOS signaling pathway is critical for maintenance of endothelial vascular tone, and integrity ${ }^{[7,8]}$. We have previously demonstrated that NOS signaling and p38 MAPK are significantly implicated in the development of acute lung injury ${ }^{[9,10]}$. Though the PI3K/Akt and MAPKs, which include the ERK1/2, JNK, and p38 MAPK subgroups, are probably the best-characterized survival-related or death-associated signaling pathways ${ }^{[11-15]}$ respectively, their functional roles in the VALI, especially the interplay between these two pathways, have not yet been elucidated. The emerging evidence has triggered interest on the crosstalk link between PI3K/ Akt and MAPKs signaling ${ }^{[16-19]}$

The purpose of this study is to identify the protective role of PI3K/Akt/eNOS signaling in the context of the lung vascular permeability in response to mechanical stress and to ascertain if this protective effect occurs via p38 MAPK signaling in murine $\mathrm{HV}_{\mathrm{T}} \mathrm{MV}$ and cyclic stretch models. Our results indicate that the PI3K/Akt/eNOS pathway is involved in the process of $\mathrm{HV}_{\mathrm{T}} \mathrm{MV}$ with a change in phosphorylated forms in intact lungs. Furthermore, genetic deletion of eNOS exacerbates vascular dysfunction as assessed by Evans Blue Dye (EBD). Finally, the findings that pharmacologic antagonism of PI3K with Wort potentiates phosphorylation of p38 MAPK in response to cyclic stretch in C10 epithelial cells and that inhibition of p38 MAPK facilitates the activation of Akt, a survival signaling protein, suggest interplay between the Akt and p38 MAPK pathways in vascular barrier dysfunction ${ }^{[20]}$.

\section{Materials and methods Materials}

CMRL 1066 medium was purchased from Invitrogen (Carlsbad, CA), and fetal bovine serum was obtained from Hyclone (Logan, UT) and Invitrogen (Carlsbad, CA). Wortmannin was obtained from Calbiochem (San Diego, CA). Phospho-specific antibodies of PI3K, Akt, and eNOS as well as p38 MAP kinase were obtained from Cell Signaling Technology (Beverly, MA). SB203580 and other reagents used in this study were obtained from Sigma (St Louis, MO).

\section{Animal model of VILI and drug administration}

Male C57BL/6J mice aged 10 weeks (23-25 g, Jackson Laboratory, Bar Harbor, ME) were studied in a pathogen-free facility under a protocol approved by the Johns Hopkins University Department of Laboratory Animal Medicine. Anesthesia was induced with sodium pentobarbital (50 mg/kg, ip). Animals then underwent tracheotomy and intubation prior to exposure to MV (Harvard Apparatus, Boston, MA) with room air for 0 (Control, Cont), 2, or $4 \mathrm{~h}$ with either $7 \mathrm{~mL} / \mathrm{kg}$ or $20 \mathrm{~mL} / \mathrm{kg}$ tidal volume $\left(\mathrm{LV}_{\mathrm{T}}\right.$ or $\left.\mathrm{HV}_{\mathrm{T}}\right)$. The respiratory rate was set at 160 breaths per minute for all tidal volumes together with an adjustment of the dead space to maintain arterial $\mathrm{pH}$ between
7.35 and 7.45. Airway pressures were continuously measured and remained around $0-2 \mathrm{~cm} \mathrm{H}_{2} \mathrm{O}$. A $500-\mu \mathrm{L}$ bolus of lactated Ringer's solution was given intravenously at the initiation of MV to maintain adequate mean arterial blood pressure (about 80 Torr) during $4 \mathrm{~h}$ of ventilation. The adequacy of MV settings on gas exchange was evaluated according to the mean blood pressure (MBP) and the arterial blood gases obtained via catheterization of a femoral artery. Rectal temperature was maintained near $37^{\circ} \mathrm{C}$ using a heating lamp and pad. At the end of $\mathrm{MV}$, the animals were administered an intraperitoneal lethal dose of the anesthetic agent before the lungs were harvested.

To assess the effect of MV on the signaling of PI3K/Akt/ eNOS and p38 MAPK, mice were treated with either a specific inhibitor of p38 MAPK, SB203580 (2 mg/ kg, ip), or a specific inhibitor of PI3K, Wort $(100 \mathrm{nmol} / \mathrm{L}, \mathrm{ip})^{[21]}, 1 \mathrm{~h}$ before exposure to MV. SB203580 and Wort were dissolved in DMSO first and then diluted further by saline. All doses, route of administration, and timing of delivery of pharmacological agents as well as the solvent were based on known half-life of agents and preliminary experiments that demonstrated efficacy ${ }^{[22,23]}$.

\section{Assessment of pulmonary capillary permeability}

Acute changes in vascular permeability were evaluated by using bronchoalveolar lavage (BAL) fluid albumin concentrations and EBD assay in intact mice. Pulmonary edema formation was also assessed using lung wet-to-dry weight (W/D) ratios. EBD $(20 \mathrm{mg} / \mathrm{kg})$ was injected into the external jugular vein $60 \mathrm{~min}$ prior to termination of the experiment to determine vascular leak as previously described ${ }^{[2,25]}$. To determine wet-to-dry lung weight ratio, as a separate measure of pulmonary edema, briefly the left lung was excised and immediately weighed on pre-tared dishes for determination of wet lung weight. The samples were then dried in an oven (Fisher Isotemp) of $60{ }^{\circ} \mathrm{C}$ for $7 \mathrm{~d}$ and weighed several times until the weight became consistent ${ }^{[26]}$.

\section{Cyclic stretch (CS) and C10, epithelial cell culture}

C10, a murine nonmalignant alveolar type II-like epithelial cell line, was cultured in CMRL 1066 medium supplemented with $10 \%$ fetal bovine serum (FBS) and antibiotics. Cells were seeded at standard densities $\left(8 \times 10^{5}\right.$ cells/well) onto collagen I-coated BioFlex plates, and once confluence was reached, the plates were mounted onto the FX-4000T Flexercell Tension Plus system (Flexercell International, McKeesport, PA) equipped with a 25-mm BioFlex loading station. This system provides uniform radial and circumferential strain across a membrane surface along all radii. Cells were subjected to $18 \%$ elongation for the desired time at 25 cycles per minute. Cells grown on BioFlex plates and simultaneously placed in a cell culture incubator were considered as static controls. At the end of the experiment, the cells were harvested for protein analysis.

\section{SDS-PAGE and immuno-blotting analysis}

Aliquots from cell lysates and tissue homogenates were immunoblotted using native and phosphospecific antibodies 
as previously described ${ }^{[9]}$. The blots were then visualized with the ECL Western Blot Detection Kit (Amersham, Piscataway, NJ, USA).

\section{Statistics}

Data are shown as mean \pm standard deviation (SD), for each experimental condition. Comparisons between groups were performed using $t$-tests or one-way ANOVA with Bonferroni correction. Analysis of variance for comparison of the different groups was used with significance set at $P<0.05$.

\section{Results}

The signaling pathway of PI3K/Akt/eNOS in response to MV

Immunoblot analysis for phospho-specific (active) and total isoforms of PI3K, Akt and eNOS was performed on lung tissue homogenates obtained from wild type mice subjected to MV with $\mathrm{HV}_{\mathrm{T}}$ for 0 (Control), 15, 30, 60, or $120 \mathrm{~min}$. As demonstrated in Figure $1 \mathrm{~A}, \mathrm{MV}$ at $\mathrm{HV}_{\mathrm{T}}$ induced a decrease in PI3K, Akt and eNOS phosphorylation as early as 30 min after initiation of MV. Figures 1B, 1C and 1D show the densitometry of phospho-PI3K, phopho-Akt, and phospho-eNOS normalized to total Akt. When we extended the experiment to $4 \mathrm{~h} \mathrm{HV}_{\mathrm{T}}$ $\mathrm{MV}$, a consistent change of phosphor-Akt was observed (Figure 2).

eNOS signaling is required for maintaining the integrity of the pulmonary vasculature

To define the role of eNOS in pulmonary permeability associated with VALI, we obtained $\mathrm{eNOS}^{-/-}$mice from the same strain background as its wild type and exposed both to MV for up to $4 \mathrm{~h}$ at $\mathrm{LV}_{\mathrm{T}}(7 \mathrm{~mL} / \mathrm{kg})$ or HVT $(20 \mathrm{~mL} / \mathrm{kg})$ at 160 BPM. Peak airway pressure was monitored continuously as detailed in Methods. Pulmonary vascular leakage was assessed by the extravasation of EBD into lung parenchyma. MV with $\mathrm{LV}_{\mathrm{T}}$
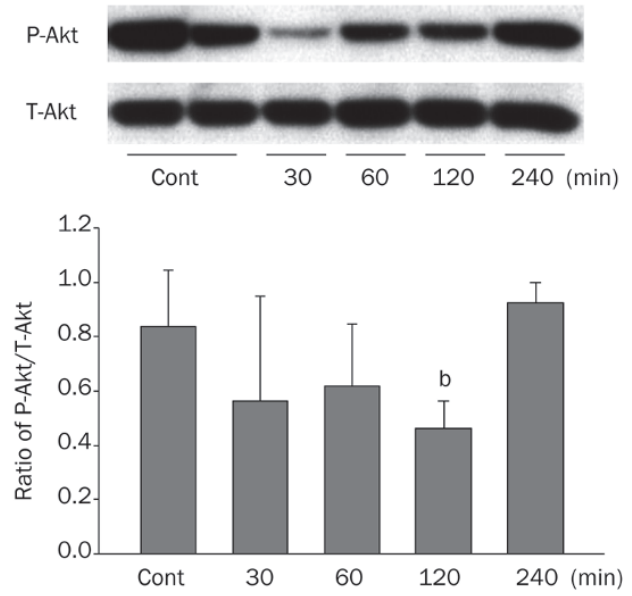

Figure 2. Down-regulation of phospho-Akt in response to mechanical stress in a time-dependent fashion. (A) In a separate experiment of $4 \mathrm{~h} \mathrm{HV}_{\mathrm{T}} \mathrm{MV}$, we observed that phospho-Akt at its serine residue 473 decreased most noticeably at $30 \mathrm{~min}$ and then gradually returned to control level at $2 \mathrm{~h}$. (B) shows the densitometry of phopho-Akt normalized to total Akt. $n=3-4$ mice per condition, ${ }^{b} P<0.05$.

caused no change in extravasation of EBD in WT mice, but caused a remarkable increase of EBD leakage in $\mathrm{eNOS}^{-/-}$mice lungs. $\mathrm{HV}_{\mathrm{T}} \mathrm{MV}$ caused a $50 \%$ increase of EBD in WT mice lungs and a further increase of about $100 \%$ in $\mathrm{eNOS}^{-/-}$mice (Figure 3).

Wet/dry lung weight ratios, a separate measure of pulmonary edema, showed that $4 \mathrm{~h}$ of $\mathrm{LV}_{\mathrm{T}} \mathrm{MV}$ increased this ratio, but not significantly. $\mathrm{HV}_{\mathrm{T}} \mathrm{MV}$ caused more remarkable lung water retention in $\mathrm{eNOS}^{-/-}$mice than in WT mice (Figure 4). No difference was observed between $\mathrm{WT}$ and $\mathrm{eNOS}^{-/-}$mice at the control condition (results not shown).
A

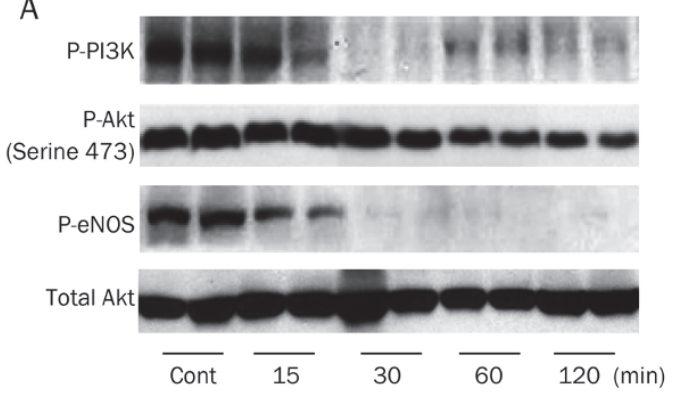

C

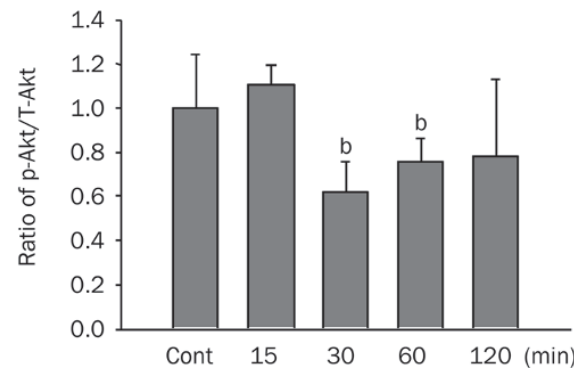

B

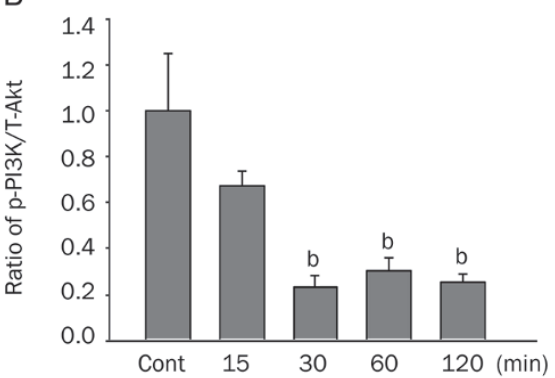

D

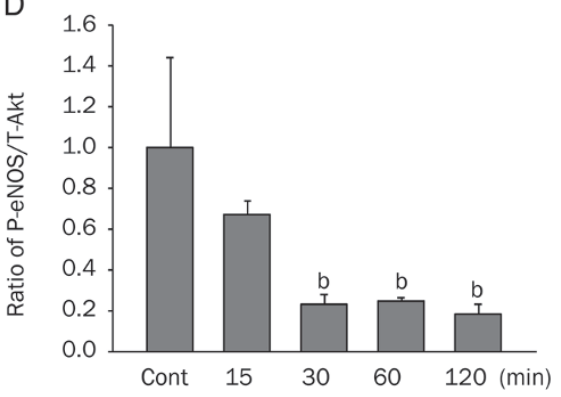

Figure 1. The signaling pathway of $\mathrm{PI} 3 \mathrm{~K} / \mathrm{Akt} / \mathrm{eNOS}$ in response to $\mathrm{MV}$. C57BL/6J mice were randomly exposed to spontaneous breathing (Control, Cont) or $\mathrm{HV}_{\mathrm{T}}(20 \mathrm{~mL} / \mathrm{kg})$ for 2 h. (A) Immunoblotting of WT mouse lung homogenates shows a decrease in $\mathrm{PI} 3 \mathrm{~K}$, Akt, and eNOS phosphorylation after initiation of $\mathrm{HV}_{\mathrm{T}} \mathrm{MV}$ detected by their active forms of antibody. (B), $(C)$, and (D) show the densitometry of phospho-PI3K, phopho-AKT, and phospho-eNOS normalized to total Akt. $n=3-4$ mice per condition, ${ }^{b} P<0.05$ vs control. Note: the Figure 1A P-Akt bands represented a combination of the results came from several experiments. 


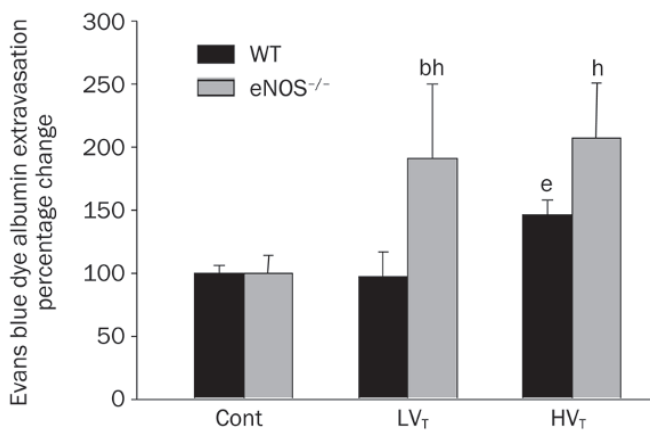

Figure 3. eNOS defective mice are less tolerant than WT mice in response to high amplitude mechanical stress featured with severe lung edema. Pulmonary vascular leakage was assessed at $4 \mathrm{~h}$ by the extravasation of evans blue dye(EBD) albumin in the lung parenchyma. MV with $\mathrm{LV}_{T}$ caused no change in EBD influx in C57BL/6J mouse lungs, but caused a marked increase of EBD extravasation in eNOS ${ }^{-1-}$ mouse lungs. In addition, $\mathrm{HV}_{\mathrm{T}} \mathrm{MV}$ caused a $100 \%$ increase of $\mathrm{EBD}$ in $\mathrm{eNOS}^{-/-}$mouse lung in comparison with a $50 \%$ increase of EBA in WT mice. $n=4$ mice/ experimental condition. ${ }^{\mathrm{b}} P<0.05$ vs Control; ${ }^{\mathrm{e}} P<0.05$ vs $\mathrm{LV}_{T} ;{ }^{\mathrm{h}} P<0.05$ vs WT vent-exposed mice.

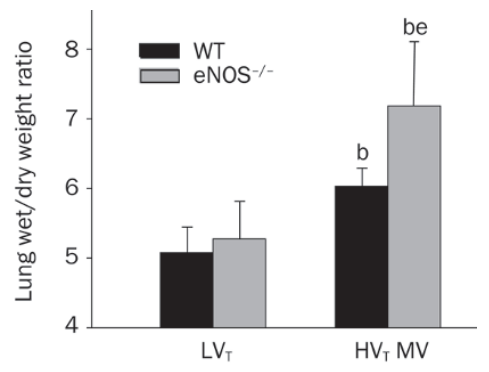

Figure 4. Effects of eNOS deficiency on pulmonary vascular leakage during mechanical ventilation. As a separate measure of pulmonary edema, wet/dry lung weight ratios were determined at the end of $4 \mathrm{~h} \mathrm{HV}_{\mathrm{T}}$ $\mathrm{MV}$. $\mathrm{HV}_{\mathrm{T}} \mathrm{MV}$ caused an increase of the lung wet-dry weight ratio especially in eNOS-deficient mice. $n=4$ mice/experimental condition. ${ }^{b} P<0.05 v s \mathrm{LV}_{T}$ exposed animals; ${ }^{e} P<0.05$ compared with WT mice exposed to $H V_{T} M V$.

$\mathrm{PI}$ K/Akt regulates the protective role of eNOS in reducing the lung edema

To ascertain its upstream regulation of eNOS, we examined the expression of phospho-Akt in WT and $\mathrm{eNOS}^{-/-}$mice after MV stress. We found that phospho-Akt declined more dramatically in $\mathrm{eNOS}^{-/-}$mice in comparison with WT. In addition, there was a lower level of phospho-Akt in $\mathrm{eNOS}^{-/-}$ mice when exposed to $L_{\mathrm{T}}$ (Figure 5). To further explore the effect of this pathway on the vascular leakage associated with $\mathrm{HV}_{\mathrm{T}} \mathrm{MV}$, we then administered the PI3K inhibitor Wortmannin (Wort, $100 \mathrm{nmol} / \mathrm{L}$, ip) $1 \mathrm{~h}$ prior to $\mathrm{HV}_{\mathrm{T}} \mathrm{MV}$ exposure. At the end of the experiment, EBD assay was performed as mentioned above. As shown in Figure 6, Wort pre-treatment significantly worsened EBD lung accumulation in WT mice triggered by $4 \mathrm{~h} \mathrm{HV}_{\mathrm{T}} \mathrm{MV}$ in comparison with the non-treated group. The morphology of the lungs demonstrated a consis-
A

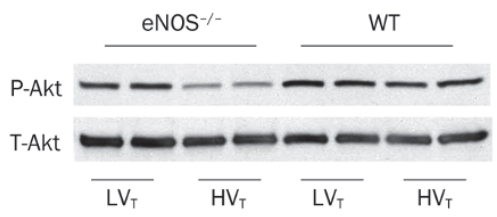

B

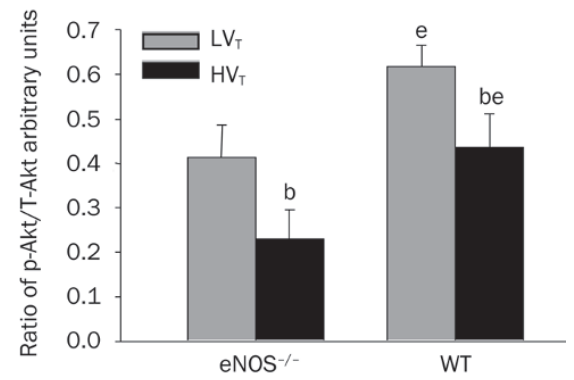

Figure 5. Lower levels of phosph-Akt expression in eNOS ${ }^{-/-}$mice compared with WT mice after exposure to mechanical stress. We specifically evaluated the level of phosphor-Akt, a survivor signal in response to a variety of stresses, in our 4-h VALI model by immunoblotting. (A) Consistent with our data above, decreased phopho-Akt was blunted in WT mice at the end of $4 \mathrm{~h} \mathrm{HV}_{\mathrm{T}} \mathrm{MV}$, while eNOS ${ }^{-/-}$mice showed a significant further decrease of phosphorylated Akt in response to $4 \mathrm{~h}$ $H V_{T}$ over the attenuated expression of phospho-Akt when exposed to $L V_{T}$. (B) Densitometry of phopho-Akt normalized to total Akt. $n=3-4$ mice per condition. ${ }^{\mathrm{b}} \mathrm{P}<0.05$ vs $\mathrm{LV}_{\mathrm{T}} ;{ }^{\mathrm{e}} \mathrm{P}<0.05$ vs eNOS ${ }^{-/-}$mice.

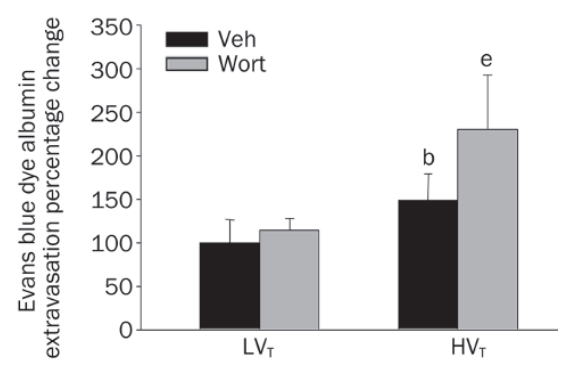

Figure 6. Wortmannin (Wort) pretreatment aggravates the pulmonary vascular leakage in WT mice induced by $4 \mathrm{~h} \mathrm{HV}$ MV. C57BL/6J mice (WT) were pretreated with Wort (100 nmol/L, given intraperitoneally), a selective PI3Kase inhibitor, $1 \mathrm{~h}$ prior to exposure to MV. Wort itself dose not have effect on EBD assay (data not shown). Exposure of animals to $\mathrm{LV}_{\mathrm{T}}$ on the other hand caused no changes in these values as compared to controls (data not shown). However, Wort pretreatment significantly enhanced EBD lung accumulation in C57BL/6J mice caused by $4 \mathrm{~h} \mathrm{HV}_{\mathrm{T}}$

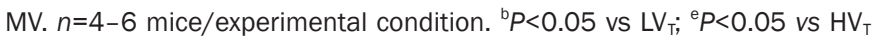
MV.

tent finding with EBD assay that Wort treatment exacerbated neutrophil infiltration and lung edema (Figures 7A, 7B). There were no striking histologic changes in lungs of C57BL/6J mice exposed to $L_{\mathrm{T}}$ as compared with control animals (results not shown).

\section{Cross-talk between p38 MAPK and PI3K/Akt/eNOS}

Given the evidence of up-regulation of p38 MAPK contributing to VALI in our murine model ${ }^{[10,22]}$, we sought to determine 


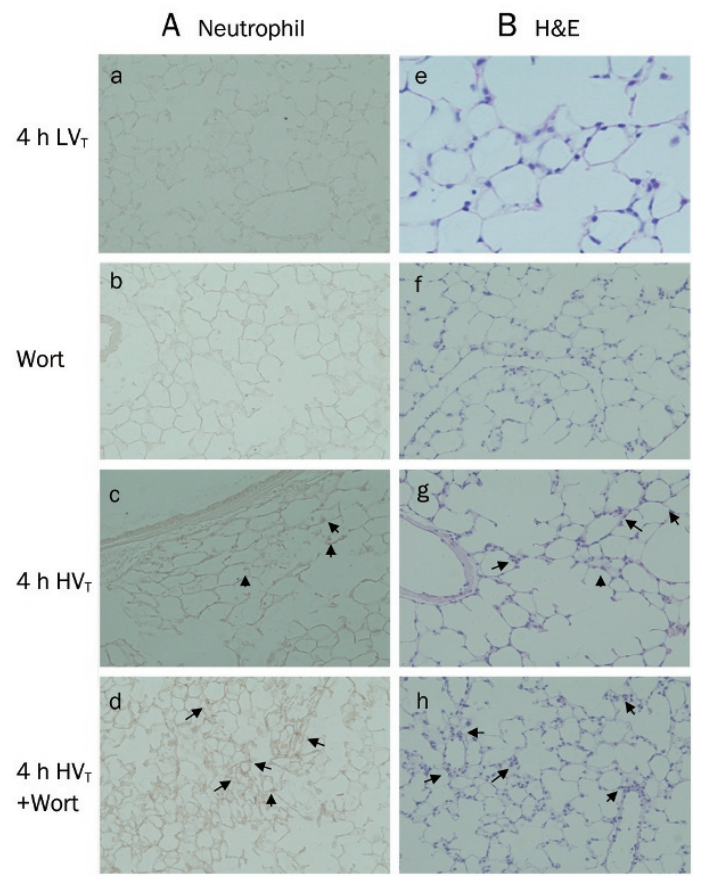

Figure 7. The morphological review of the lungs after pretreatment with Wort and mechanical ventilation. (A) Neutrophil immunostaining: the presence of parenchymal neutrophil was assessed using specific antineutrophil antibody. Exposure to $4 \mathrm{~h} \mathrm{HV}_{\mathrm{T}} \mathrm{MV}$ produced an increased staining of neutrophils in the interstitium and alveolus in WT mice (c, arrow) compared to $\mathrm{LV}_{\mathrm{T}}$ and Wort only ( $\mathrm{a}$ and $\mathrm{b}$ ). However, Wort - a specific inhibitor of PI3K--pretreatment exacerbated this effect (d, arrow). (B) Hematoxyline and eosin stain of lung tissue $(\times 40)$ : the presence of neutrophil infiltration in WT mice lungs when exposed to $H V_{T}$ for $4 \mathrm{~h}$ is similar as seen on the neutrophil immuno-staining but with occasional alveolar hemorrhage (g, arrow) compared to $\mathrm{LV}_{\mathrm{T}}$ and Wort only (e and f); Wort worsened the lung injury compared to that in animals ventilated alone ( $h$, arrow). There were no striking histological changes in lungs of C57BL/6J mice exposed to $\mathrm{LV}_{\top}$ as compared with control animals (results not shown).

the possible involvement of p38 MAPK in the pathway of PI3K/Akt/eNOS. We found that pretreatment of WT mice with SB203580 (2 mg/kg, ip) $1 \mathrm{~h}$ prior to $\mathrm{HV}_{\mathrm{T}} \mathrm{MV}$ attenuated lung capillary leakage as measured by the index of BAL protein at the end of $2 \mathrm{~h} \mathrm{HV}_{\mathrm{T}} \mathrm{MV}$ (Figure 8). Recently, using the index of wet/dry lung weight ratio and EBD, we demonstrated that inhibition of the p38 MAP kinase pathway with SB203580 reduces pulmonary capillary permeability in response to high tidal volume mechanical ventilation ${ }^{[22]}$. More strikingly, at $4 \mathrm{~h}$ we found that inhibition of p38 MAPK with SB203580 treatment increased the activation of Akt in response to $\mathrm{HV}_{\mathrm{T}} \mathrm{MV}$, possibly indicating interplay between these two signaling pathways (Figure 9). To further confirm the overlapping of these two signals, we observed the effect of the PI3K inhibitor, $20 \mathrm{nmol} / \mathrm{L}$ Wort ${ }^{[27]}$, on the expression of phosphoAkt and phospho-p38 MAPK on C10 alveolar epithelial cells when exposed to $18 \%$ elongation of CS for $1-2 \mathrm{~h}$. This data demonstrated that pharmacologic antagonism of PI3K with

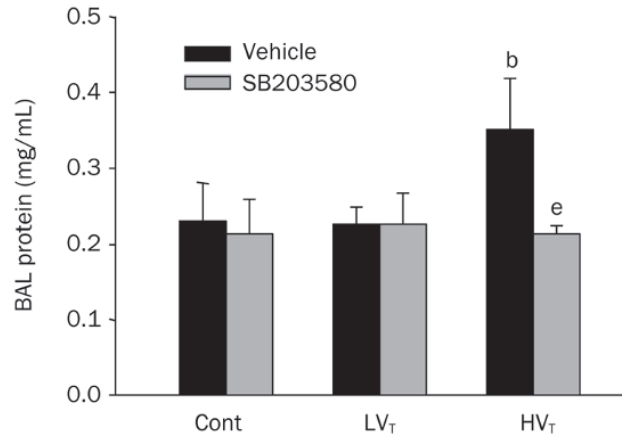

Figure 8. Inhibition of p38 MAP kinase prevents protein leakage in response to $\mathrm{HV}_{T} \mathrm{MV}$. Mice were treated with the p38 MAP kinase inhibitor SB203580 (2 mg/kg, ip) $1 \mathrm{~h}$ prior to exposure to $1-2 \mathrm{~h} \mathrm{HV}_{\mathrm{T}} \mathrm{MV}$. The data showed that the lung capillary leakage was attenuated by using the index of BAL protein at the end of $2 \mathrm{~h} \mathrm{HV} T$ MV. $n=4 .{ }^{b} P<0.05 v_{s} \operatorname{LV}_{T}$; ${ }^{e} P<0.05$ vs $2 \mathrm{~h} \mathrm{HV}$ MV.
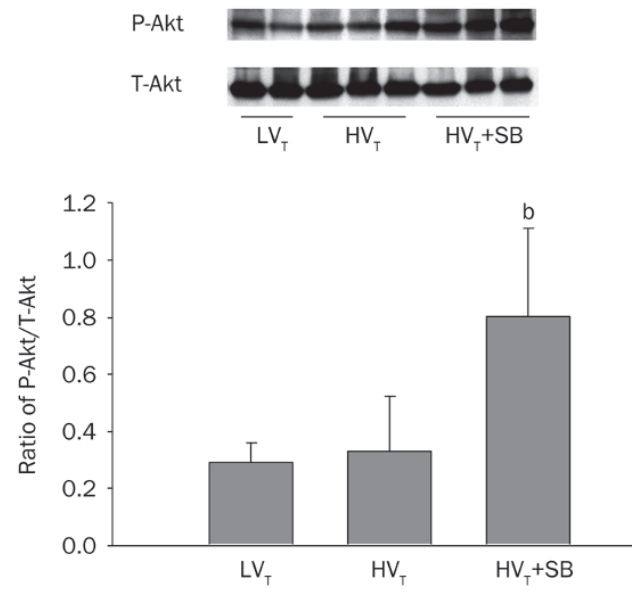

Figure 9. The effect of SB203580(SB) on the activation of Akt in WT mice exposed to $4 \mathrm{~h}$ mechanical ventilation. Western blotting on the mice lung exposed to $\mathrm{HV}_{\mathrm{T}} \mathrm{MV}$ for $4 \mathrm{~h}$ demonstrated that the inhibition of p38 MAPK with SB203580 increased the activation of Akt (serine 473 phosphorylation), indicating interplay between these two signal pathways. $n=3-4$ mice per condition. ${ }^{b} P<0.05$.

Wort diminished the activation of Akt, but potentiated phosphorylation of MAPK p38 in response to mechanical stress in cultured epithelial cells (Figure 10).

\section{Discussion}

In this study, we demonstrated that eNOS signaling is required for maintaining the integrity of the pulmonary vasculature in response to mechanical stress, and that this effect is modulated by its upstream pathway of PI3K/Akt. More importantly, we provide evidence for the first time about the existence of crosstalk of PI3K/Akt/eNOS and the p38 MAP kinase pathways in a mechanical stretch model. We demonstrate that inhibition of PI3-kinase/Akt potentiates p38 MAPK activation, while inhibition of p38 MAPK results in an increased phosphorylation of 
A

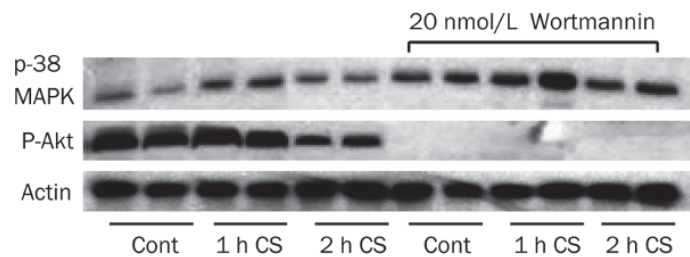

B
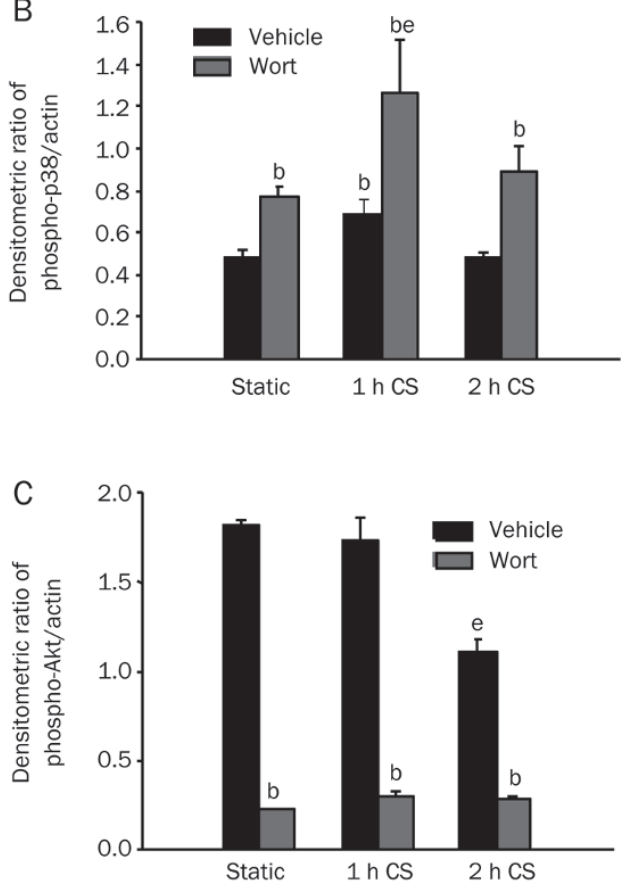

Figure 10. The effect of PI3K inhibitor, $20 \mathrm{nmol} / \mathrm{L}$ Wort, on the expression of phospho-Akt and phospho-p38 MAPK. Pharmacologic antagonism of PI3K with Wort diminished the activation of Akt, but potentiated phosphorylation of MAPK p38 in C10, type II alveolar epithelial cells when exposed to $18 \%$ cyclic stretch (CS) from 1-2 h. A) the representative blotting; $B$ and $C$ ) the densitometric ratio of phospho-p38/actin and phospho-Akt/actin. $n=3-4$. ${ }^{b} P<0.05$ vs Vehicle; ${ }^{e} P<0.05$ vs static. Note: the P-Akt bands represented a combination of the results came from several experiments.

Akt, which regulates the protective effect of eNOS against the pulmonary vascular edema associated with mechanical stress. In summary, this work, coupled with results from prior studies, demonstrates that the protective role of PI3K/Akt/eNOS signaling in mechanical stress is mediated in part via inhibition of p38 mitogen-activated protein kinase signaling.

\section{The signaling pathway of $\mathrm{PI3K} / \mathrm{Akt} / \mathrm{eNOS}$ in response to MV}

In this work, we investigated the role of PI3-kinase/Akt/ eNOS in ventilator-associated alveolar-capillary injury and dysfunction in a murine model by using $\mathrm{eNOS}^{-/-}$mice together with WT mice, and by using a pharmacological inhibitor of PI3-kinase. We found in our previous study that total eNOS signaling in intact mice lung decreased after animals were exposed to $\mathrm{HV}_{\mathrm{T}} \mathrm{MV}^{[9]}$. In the present VALI study we measured the active forms of PI3K/Akt/eNOS. We found initially that not only the phospho-eNOS signal would decrease as early as $15 \mathrm{~min}$, but also that the phosphorylation of PI3 kinase and Akt declined in the same time-dependent pattern after initiation of $\mathrm{HV}_{\mathrm{T}} \mathrm{MV}$ up to $2 \mathrm{~h}$ in WT mice lungs. This indicated that the PI3K/Akt pathway is involved in this event (Figure 1). We then extended ventilating stress to $4 \mathrm{~h}$. Immunoblotting showed the same trend of the decline in phospho-Akt as seen during the first $2 \mathrm{~h}$ of $\mathrm{HV}_{\mathrm{T}} \mathrm{MV}$. This change gradually returned toward baseline at the end of $4 \mathrm{~h} \mathrm{HV}_{\mathrm{T}} \mathrm{MV}$ (Figure 2). Given that the total Akt did not changed and all the signals were detected on the same blotting, we quantified the expression of phosphorylated PI3K/Akt/eNOS based on total Akt.

eNOS signaling is required for maintaining the integrity of the pulmonary vasculature

We further explored the role of eNOS in the pulmonary micro-vascular leakage. We found that genetic deletion of eNOS reduced the tolerance of the pulmonary endothelium to mechanical stress. MV with $\mathrm{LV}_{\mathrm{T}}$ caused no change of extravasation of EBD in wild type mice, but caused remarkable increase of EBD leakage in $\mathrm{eNOS}^{-/-}$mice lungs. $\mathrm{HV}_{\mathrm{T}} \mathrm{MV}$ caused a 50\% increase of EBD influx in the WT mice lungs and a further increase of about $100 \%$ in EBD lung accumulation in eNOS $^{-/-}$mice (Figure 3). This result was consistent with our previously published work that a declined expression of eNOS protein was associated with VALI in C57BL/6J mice, and that an increased eNOS activity was correlated with the tolerance of iNOS deficient mice to ventilator-induced pulmonary capillary leakage $\mathrm{e}^{[9]}$. This finding was also in agreement with the work of Takenaka et al, in which overexpressed eNOS in the lung could reduce VALI ${ }^{[28,29]}$.

We also observed wet/dry lung weight ratios as a separate measure of pulmonary edema to confirm the effect of eNOS influencing vascular barrier function. As shown in Figure 4, $\mathrm{HV}_{\mathrm{T}} \mathrm{MV}$ for $4 \mathrm{~h}$ caused more profound lung edema in $\mathrm{eNOS}^{-/-}$ mice than in WT mice. According to our data, the enhanced pulmonary permeability in response to mechanical stress can be explained in part by defects in eNOS signaling, a finding similar to that of a previous report in which eNOS or Akt1 deficient mice exhibited impaired blood flow recovery and neovascularization following arterial occlusion ${ }^{[30]}$ and a suppressed VEGF-induced angiogenesis and vascular permeability $^{[13]}$. Chen et al also showed that impaired vascular maturation due to loss of the gene of Akt1 $\left(\mathrm{Akt}^{-/-}\right)$in mice may be attributed to reduced activation of endothelial nitric oxide synthase (eNOS) ${ }^{[7]}$.

Lungs from eNOS-deficient animals showed less change in the index of wet/dry weight ratio compared to wild-type (WT) controls than would be expected based on the Evans blue dye assay (EBD). Pharmacokinetic analysis demonstrated that $87 \%$ of the decline in intravascular Evans blue during the first $3 \mathrm{~h}$ after administration was a result of transvascular flux to tissue compartments. Thus, the initial accrual of Evans blue in the lung and heart may be used as a marker of transcapillary macromolecular flux in those tissues ${ }^{[26]}$.

EBD mainly measures the condition of capillary permeabil- 
ity detected by albumin leaking from vasculature to the interstitial compartment. The initial decline in intravascular content of EBD corresponds to the intercompartmental clearance and to transcapillary macromolecular flux. While the wet/dry lung weight ratios measure whole lung water accumulation, this includes the three fluid compartments (vascular, interstitial and alveolar). The measurement not only reflects vascular and pulmonary permeability, but also the hydraulic pressure of the capillaries and fluid clearance of the airways.

The differences observed between the wet/dry ratio and EBD indicate that the wet/dry weight ratio is not as sensitive as the EBD assay for the evaluation of vasculature leakage. This may be due to a number of factors. First, it is likely that mechanical stretch may have non-uniform effects on protein permeability, hydraulic conductivity and fluid clearance ${ }^{[31]}$. Also, many studies showed that hydraulic conductivity increased without changes in protein permeability ${ }^{[32]}$. Furthermore, it is possible that water flux across the vascular barrier is increased with eNOS deficiency, but that edema clearance mechanisms are unaltered or in a compensatory condition, thus attenuating any differences in lung wet/dry weight between knockout and WT animals. These three factors may blunt the change of vascular permeability caused by mechanical stress, especially at the condition of $\mathrm{LV}_{\mathrm{T}} \mathrm{MV}$. We did not show the data for the spontaneously breathing in the animals because we repeatedly demonstrated in our preliminary experiments and published works that there is no difference between the control and $\mathrm{LV}_{\mathrm{T}} \mathrm{MV}$.

There is now compelling evidence supporting that endothelial NO is a barrier-tightening factor in modulating thrombin, cytokine and $\mathrm{H}_{2} \mathrm{O}_{2}$-induced endothelial permeability ${ }^{[33,34]}$. Electron microscopic analyses revealed an intercellular junction opening in lung microvasculature in $\mathrm{eNOS}^{-/-}$mice ${ }^{[35]}$. In eNOS transgenic mice there is a remarkable resistance to ventilator-induced lung injury and to bacterial lipopolysaccharide induced septic shock (with attenuated hypotension, pulmonary leukocyte infiltration and lung water content), as well as an enhanced survival rate over control mice ${ }^{[28,29]}$. Therefore, eNOS-derived nitric oxide is believed to be a determinant of endothelial junctional integrity, and eNOS will be a beneficial signaling protein protecting the vessel from leakage.

\section{$\mathrm{PI} 3 \mathrm{~K} /$ Akt regulates the protective role of eNOS in reducing the lung edema}

Recent studies indicated that Akt1 deficiency, the predominant isoform of Akt, could cause an immature development of the vasculature that is prone to leak ${ }^{[7,13]}$. In the vessel wall, the loss of Akt1 increases inflammatory mediators and reduces eNOS phosphorylation, suggesting that Akt1 exerts vascular protection against atherogenesis, in part, through the action of $\mathrm{eNOS}^{[12]}$.

Considering the link between PI3K/Akt and eNOS, eNOS signaling is necessary for maintaining the integrity of the lung vasculature after exposure to mechanical ventilation. Given that PI3K/Akt in vivo roles and the interactions with other signaling are not yet explicitly defined, we investigated the expression of phospho-Akt on the lungs of both eNOS ${ }^{-/-}$and WT mice after $4 \mathrm{~h} \mathrm{HV}$ MV. As shown in Figure 5, there was a lower level of phosphorylated-Akt detected at the residue of serine 473 respond to both $\mathrm{LV}_{\mathrm{T}}$ and $\mathrm{HV}_{\mathrm{T}} \mathrm{MV}$ in eNOS $\mathrm{NO}^{-/-}$mice compared to WT mice. This may suggest a mechanism related to a vulnerability of eNOS ${ }^{-/-}$mice in response to mechanical stress. In addition, these data may suggest a possible feedback role of eNOS deficiency on Akt activation.

Chen and colleagues reported a modest decrease in the basal levels of active eNOS in endothelial cells isolated from $\mathrm{Akt1}^{-/-}$ mice when compared to wild-type mice ${ }^{[7]}$. Interestingly, our experimental data demonstrated that deletion of the eNOS gene could decrease the activation of Akt both at the physiological condition and when the animal responds to high tidal volume mechanical stretch.

The direct role of Akt in the maintenance of vascular permeability was further supported by our observation that pretreatment with Wort, a pharmacological inhibitor of PI3K, significantly worsened EBD lung accumulation in WT mice induced by $4 \mathrm{~h} \mathrm{HV}$ T MV (Figure 6). In addition, H\&E staining and neutrophil immunostaining in the lungs showed an enhanced interstitial and alveolar infiltration of neutrophils in WT mice pretreated with Wort and exposed to $4 \mathrm{~h} \mathrm{HV}_{\mathrm{T}}$ MV compared with vehicle (Figures 7A, 7B). These findings indicate that phospho-Akt plays an essential role in modulating eNOS-regulated vascular permeability and suggest an upstream regulatory role of PI3K/Akt on eNOS in our model.

\section{Cross-talk between p38 MAPK and PI3K/Akt/eNOS}

In recent years, the emerging evidence has triggered the interests on the crosstalk between PI3K/Akt and MAPKs signalings ${ }^{[18,19,36,37]}$. The important reason for elucidating the interplay of the PI3K/Akt and p38 MAPK pathways is that the former pathway is the best-characterized survivalrelated system and the latter is a death-associated signaling pathway ${ }^{[13]}$. Many studies have suggested a close relationship between NOS/NO expression and p38 phosphorylation ${ }^{[17,38,39]}$. Data from our study shows that inhibition of p38 MAPK by SB203580 increased the activation of Akt in response to $\mathrm{HV}_{\mathrm{T}}$ MV and decreased the lung edema. Our recently published work demonstrated that inhibition of the p38 MAP kinase pathway prevents EBD extravasations and water retention in mice lungs in response to high tidal volume mechanical ventilation $^{[22]}$. Thus, in this study, we mainly focused on the signaling pathway PI3K/Akt / eNOS using Wort on EBD and wet/ dry ratio observations instead of inhibition of both pathways. Furthermore, given the awareness that phosphorylation of Akt triggered by $\mathrm{HV}_{\mathrm{T}} \mathrm{MV}$ has resolved by $4 \mathrm{~h}$ ventilation and the evidence of the severe lung edema and injury at this time point, we observed the interaction between the two signals by applying the PI3K inhibitor, Wort, to evaluate p38 MAPK change. The PI3K inhibitor, Wort, potentiated phosphorylation of p38 MAPK in response to mechanical stretch, suggesting a possible mechanism of modulation between parallel signaling pathways at this time point ${ }^{[40]}$. Based on the results we published before that the peak of phosphorylated P38 MAPK 
expression is around 60 min before it returns back during the $2 \mathrm{~h} \mathrm{HV}_{\mathrm{T}} \mathrm{MV}$ and the lung injuries were seen at either $2 \mathrm{~h}$ or $4 \mathrm{~h}$ $\mathrm{HV}_{\mathrm{T}} \mathrm{MV}$, we believe that the suppressed protective pathway of PI3K/Akt/eNOS in the $4 \mathrm{~h} \mathrm{HV}_{\mathrm{T}} \mathrm{MV}$ was mediated by upregulation of p38 MAPK. Thus, maintaining a normal level of $\mathrm{PI} 3 \mathrm{~K} / \mathrm{Akt} / \mathrm{eNOS}$ may negate the p38 MAPK role attributed to VALI.

Our results are in agreement with the report that PI3kinase/Akt signaling promotes endothelial cell survival by inhibiting p38 MAPK-dependent apoptosis, because Akt may cause MEKK3 phosphorylation, an upstream regulator of p38 MAPK. The phosphorylated form of MEKK3 decreases MEKK3 kinase activity leading to down-regulation of MKK3/6 and p38 MAPK activation ${ }^{[21]}$.

Therefore, we conclude that protection of capillary leakage was associated with activation of Akt and attenuation of p38 MAPK expression. In addition, eNOS deficient mice were prone to $\mathrm{HV}_{\mathrm{T}} \mathrm{MV}$-mediated injury. The crosstalk between the two signaling pathways shown above may govern the differential effects of PI3K/Akt/eNOS and p38 MAPK on vascular barrier function in our experimental setting. The finding that $\mathrm{PI} 3 \mathrm{~K} / \mathrm{Akt} / \mathrm{eNOS}$ has a critical role in maintaining the integrity of vasculature through inhibition of p38 MAPK deepens our insight and has potential therapeutic implications.

\section{Acknowledgements}

This work was supported by grants from American Heart Association (Mid-Atlantic, Beginning Grant-in-Aid \#0765286U), American Lung Association of Maryland (Biomedical Research Grant, 2006) and the National Heart, Lung and Blood Institute (NIH R01 HL049441; P50 HL 73994).

The authors thank Drs Hunter C CHAMPION, Allan CHESLEY and Michael T CROW for helpful consultation and technical assistance. We thank CPT Gleeson MURPHY and Ms Cindy A KRONMAN for critical reading.

Finally, I give heartfelt love and gratitude to my father, $\mathrm{Mr}$ Yun-xiang PENG, for his unconditional love and support on my effort to get funding for this work.

\section{Author contribution}

Xin-qi PENG is responsible for the overall administration and direction of the project, who contributed to the design, conducting, data assessment, and the publication of the results for this study; Jun-tian ZHANG contributed to the conducting and the publication of the work; Mahendra DAMARLA and Stephanie NONAS helped with the project funding and provided comments as well as assisted in the interpretation of the research; Jarrett SKIRBALL, Emile J HASAN, Xuan CAO and Adel BOUEIZ helped on performing the research; Eugenia J HAN helped on the writing for the project funding and performed the research; Xuan CAO, Xiao-ying WANG, Dana R ANDERSON and Alfred M SCIUTO helped on the paper writing; Rubin M TUDER helped on reviewing the results of the morphology and immuno-histochemistry; Rachel DAMICO provided comments on this study; David A KASS, Joe GN GARCIA and Alfred M SCIUTO contributed as consultants on this study; Paul M HASSOUN provided part of funding for this study and assisted the first author in interpretation of the data as well as contributed as a consultant.

\section{References}

1 Ware LB, Matthay MA. The acute respiratory distress syndrome. N Engl J Med 2000; 342: 1334-49.

2 Peng X, Hassoun PM, Sammani S, McVerry BJ, Burne MJ, Rabb $\mathrm{H}$, et al. Protective effects of sphingosine 1-phosphate in murine endotoxin-induced inflammatory lung injury. Am J Respir Crit Care Med 2004; 169: 1245-51.

3 Miyahara T, Hamanaka K, Weber DS, Drake DA, Anghelescu M, Parker JC. Phosphoinositide 3-kinase, Src, and Akt modulate acute ventilation-induced vascular permeability increases in mouse lungs. Am J Physiol Lung Cell Mol Physiol 2007; 293: L11-21.

4 Dimmeler S, Fleming I, Fisslthaler B, Hermann C, Busse R, Zeiher AM. Activation of nitric oxide synthase in endothelial cells by Aktdependent phosphorylation. Nature 1999; 399: 601-5.

5 Go YM, Boo YC, Park H, Maland MC, Patel R, Pritchard KA Jr, et al. Protein kinase B/Akt activates c-Jun $\mathrm{NH}$ 2-terminal kinase by increasing NO production in response to shear stress. J Appl Physiol 2001; 91: $1574-81$.

6 Iwakiri Y, Tsai MH, McCabe TJ, Gratton JP, Fulton D, Groszmann RJ, et al. Phosphorylation of eNOS initiates excessive NO production in early phases of portal hypertension. Am J Physiol Heart Circ Physiol 2002; 282: H2084-90.

7 Chen J, Somanath PR, Razorenova O, Chen WS, Hay N, Bornstein P, et al. Akt1 regulates pathological angiogenesis, vascular maturation and permeability in vivo. Nat Med 2005; 11: 1188-96.

8 Yu J, deMuinck ED, Zhuang Z, Drinane M, Kauser K, Rubanyi GM, et al. Endothelial nitric oxide synthase is critical for ischemic remodeling, mural cell recruitment, and blood flow reserve. Proc Natl Acad Sci USA 2005; 102: 10999-1004.

9 Peng X, Abdulnour RE, Sammani S, Ma SF, Han EJ, Hasan EJ, et al. Inducible nitric oxide synthase contributes to ventilator-induced lung injury. Am J Respir Crit Care Med 2005; 172: 470-9.

10 Abdulnour RE, Peng X, Finigan JH, Han EJ, Hasan EJ, Birukov KG, et al. Mechanical stress activates xanthine oxidoreductase through MAP kinase-dependent pathways. Am J Physiol Lung Cell Mol Physiol 2006; 291: L345-53.

11 Dimmeler S, Zeiher AM. Nitric oxide-an endothelial cell survival factor. Cell Death Differ 1999; 6: 964-8.

12 Fernández-Hernando C, Ackah E, Yu J, Suárez Y, Murata T, Iwakiri $\mathrm{Y}$, et al. Loss of Akt1 leads to severe atherosclerosis and occlusive coronary artery disease. Cell Metab 2007; 6: 446-57.

13 Ackah E, Yu J, Zoellner S, Iwakiri Y, Skurk C, Shibata R, et al. Akt1/ protein kinase Balpha is critical for ischemic and VEGF-mediated angiogenesis. J Clin Invest 2005; 115: 2119-27.

14 Kim HJ, Lee HS, Chong YH, Kang JL. p38 Mitogen-activated protein kinase up-regulates LPS-induced NF-kappaB activation in the development of lung injury and RAW 264.7 macrophages. Toxicology 2006; 225: 36-47.

15 Morrell ED, Tsai BM, Wang M, Crisostomo PR, Meldrum DR. p38 mitogen-activated protein kinase mediates the sustained phase of hypoxic pulmonary vasoconstriction and plays a role in phase I vasodilation. J Surg Res 2006; 134: 335-41.

16 Lee ER, Kim JY, Kang YJ, Ahn JY, Kim JH, Kim BW, et al. Interplay between PI3K/Akt and MAPK signaling pathways in DNA-damaging drug-induced apoptosis. Biochim Biophys Acta 2006; 1763: 958-68.

17 Xing F, Jiang Y, Liu J, Zhao K, Mo Y, Liu Z, et al. Downregulation of 
human endothelial nitric oxide synthase promoter activity by $\mathrm{p} 38$ mitogen-activated protein kinase activation. Biochem Cell Biol 2006; 84: $780-8$.

18 Kristof AS, Fielhaber J, Triantafillopoulos A, Nemoto S, Moss J. Phosphatidylinositol 3-kinase-dependent suppression of the human inducible nitric-oxide synthase promoter is mediated by FKHRL1. J Biol Chem 2006; 281: 23958-68.

19 Liagre B, Leger DY, Vergne-Salle P, Beneytout JL. MAP kinase subtypes and Akt regulate diosgenin-induced apoptosis of rheumatoid synovial cells in association with COX-2 expression and prostanoid production. Int J Mol Med 2007; 19: 113-22.

20 Peng X, Damarla M, Damico R, Hasan H, Boueiz A, Pae HH, et al. Protective role of PI3-kinase/akt signaling in mechanical stress through inhibition of p38 mitogen-activated protein kinase signaling. Am J Respir Crit Care Med 2008; 177(Abstracts issue): A760.

21 Gratton JP, Morales-Ruiz M, Kureishi Y, Fulton D, Walsh K, Sessa WC. Akt down-regulation of p38 signaling provides a novel mechanism of vascular endothelial growth factor-mediated cytoprotection in endothelial cells. J Biol Chem 2001; 276: 30359-65.

22 Damarla M, Hasan E, Boueiz A, Le A, Pae HH, Montouchet C, et al. Mitogen activated protein kinase activated protein kinase 2 regulates actin polymerization and vascular leak in ventilator associated lung injury. PLoS One 2009; 4: e4600.

23 Le A, Damico R, Damarla M, Boueiz A, Pae HH, Skirball J, et al. Alveolar cell apoptosis is dependent on p38 MAP kinase-mediated activation of xanthine oxidoreductase in ventilator-induced lung injury. J Appl Physiol 2008; 105: 1282-90.

24 Green TP, Johnson DE, Marchessault RP, Gatto CW. Transvascular flux and tissue accrual of Evans blue: effects of endotoxin and histamine. J Lab Clin Med 1988; 111: 173-83.

25 Rossner W, Tempel K. Quantitative determination of the permeability of the so-called blood-brain barrier of Evans blue (T 1824). Med Pharmacol Exp Int J Exp Med 1966; 14: 169-82.

26 Becker PM, Kazi AA, Wadgaonkar R, Pearse DB, Kwiatkowski D, Garcia JG. Pulmonary vascular permeability and ischemic injury in gelsolindeficient mice. Am J Respir Cell Mol Biol 2003; 28: 478-84.

27 Peng X, Haldar S, Deshpande S, Irani K, Kass DA. Wall stiffness suppresses Akt/eNOS and cytoprotection in pulse-perfused endothelium. Hypertension 2003; 41: 378-81.

28 Yamashita T, Kawashima S, Ohashi Y, Ozaki M, Ueyama T, Ishida T, et al. Resistance to endotoxin shock in transgenic mice overexpressing endothelial nitric oxide synthase. Circulation 2000; 101: 931-7.

29 Takenaka K, Nishimura Y, Nishiuma T, Sakashita A, Yamashita T,
Kobayashi K, et al. Ventilator-induced lung injury is reduced in transgenic mice that overexpress endothelial nitric oxide synthase. Am J Physiol Lung Cell Mol Physiol 2006; 290: L1078-86.

30 Emanueli C, Monopoli A, Kraenkel N, Meloni M, Gadau S, Campesi I, et al. Nitropravastatin stimulates reparative neovascularisation and improves recovery from limb Ischaemia in type-1 diabetic mice. $\mathrm{Br} J$ Pharmacol 2007; 150: 873-82.

31 Vincent PA, Kreienberg PB, Minnear FL, Saba TM, Bell DR. Simultaneous measurement of fluid and protein permeability in isolated rabbit lungs during edema. J Appl Physiol 1992; 73: 2440-7.

32 Ehrhart IC, Hofman WF. Pressure-dependent increase in lung vascular permeability to water but not protein. J Appl Physiol 1992; 72: 211-8.

33 Draijer R, Atsma DE, van der Laarse A, van Hinsbergh VW. cGMP and nitric oxide modulate thrombin-induced endothelial permeability. Regulation via different pathways in human aortic and umbilical vein endothelial cells. Circ Res 1995; 76: 199-208.

34 Wong D, Dorovini-Zis K, Vincent SR. Cytokines, nitric oxide, and cGMP modulate the permeability of an in vitro model of the human bloodbrain barrier. Exp Neurol 2004; 190: 446-55.

35 Predescu D, Predescu S, Shimizu J, Miyawaki-Shimizu K, Malik AB. Constitutive eNOS-derived nitric oxide is a determinant of endothelial junctional integrity. Am J Physiol Lung Cell Mol Physiol 2005; 289: L371-81.

36 Lee ER, Kim JY, Kang YJ, Ahn JY, Kim JH, Kim BW, et al. Interplay between PI3K/Akt and MAPK signaling pathways in DNA-damaging drug-induced apoptosis. Biochim Biophys Acta 2006; 1763: 958-68.

37 Xing F, Jiang Y, Liu J, Zhao K, Mo Y, Liu Z, et al. Downregulation of human endothelial nitric oxide synthase promoter activity by $\mathrm{p} 38$ mitogen-activated protein kinase activation. Biochem Cell Biol 2006; 84: $780-8$.

38 Gao X, Wang H, Sairenji T. Inhibition of Epstein-Barr virus (EBV) reactivation by short interfering RNAs targeting p38 mitogen-activated protein kinase or c-myc in EBV-positive epithelial cells. J Virol 2004; 78: 11798-806.

39 Brahmbhatt S, Gupta A, Sharma AC. Bigendothelin-1 (1-21) fragment during early sepsis modulates tau, p38-MAPK phosphorylation and nitric oxide synthase activation. Mol Cell Biochem 2005; 271: $225-$ 37.

40 Lv GF, Chen B, Zhang WF, Wang YC, Zhu XX, Hu DH. Study on crosstalk between phosphatidylinositol 3-kinase/Akt pathway and p38 mitogenactivated protein kinase pathway in cardiomyocyte with challenge of burn serum. Zhonghua Shao Shang Za Zhi 2008; 24: 263-7. 